\title{
Telejornalismo e autenticação do real: estratégias, espaços e acontecimentos
} Bruno Souza Leal

\section{Resumo}

0 artigo busca identificar e avaliar algumas estratégias de autenticação da notícia no telejornalismo, tendo em vista especialmente as relações que envolvem a produção do acontecimento jornalístico. As reflexões partem de análises de matérias e procedimentos do Jornal Nacional, da TV Globo, ao longo de 2007 e 2008.

Palavras-chave

Televisão. Jornalismo. Narrativa. Acontecimento.

Bruno Souza Leal | brunosleal@gmail.com

Doutor em Estudos Literários pela Universidade Federal de Minas Gerais - UFMG. Coordenador do Programa de Pós-Graduação em Comunicação da UFMG.

\section{Introdução}

Este artigo tem como propósito identificar e avaliar algumas das estratégias de autenticação da notícia no telejornalismo, tendo em vista as relações que envolvem a produção do acontecimento jornalístico. As reflexões aqui desenvolvidas partem de análises de matérias e procedimentos do Jornal Nacional, da TV Globo, ao longo de 2007 e 2008. Mais que simples espelhos do real, as notícias são vistas como elementos importantes na conformação da experiência contemporânea, uma vez mesmo que elas se apresentam como acontecimentos na vida dos seus diversos consumidores. Esse acontecer da notícia faz ressaltar sua forma marcadamente narrativa, cuja existência, parafraseando o que disse Barthes (1987) há quarenta anos, se dá não em função de sua origem, mas da sua recepção. A multiplicidade da qual é composta a notícia - e aí se incluem suas condições de produção - tem um destino, um fim, um lugar: 0 aqui agora dos receptores. É exatamente a dinâmica de construção e autenticação dos acontecimentos noticiosos, 
desejosos por serem recebidos, que se tem em vista aqui.

\section{0 acontecimentos e seus problemas}

Segundo Louis Quéré (2005), a experiência social se dá através dos diversos acontecimentos - grandes ou pequenos, fortes ou fracos que ocorrem no cotidiano e que articulam dialeticamente identidade e diferença, continuidade e descontinuidade, presente/ passado/futuro. Um acontecimento, diz 0 sociólogo francês, contém sempre uma diferença dos outros, o que faz com que sua existência seja condicionada, mas não determinada, pela situação histórica, uma vez mesmo que sua emergência contém elementos de novidade, de ruptura, de rearticulação das relações sociais que lhe dão origem. Visto sob um ângulo pragmático e hermenêutico, o acontecimento é, portanto, percebido como dotado de "passibilidade" e "poder hermenêutico", ou seja, da capacidade de afetar os sujeitos, exigindolhes compreensão e ação. Com isso, tendo em vista os diferentes acontecimentos que surgem no cotidiano, Quéré observa e problematiza a distância entre fato e sentido, apontando que aquele é ao mesmo tempo explicável e explicativo. Em outras palavras, como observa José Rebelo (2005), um acontecimento é explicável - tornando-se "fato" pela produção de narrativas - e explicativo - "pelo poder que transporta, como revelador daquilo que transforma, nas coisas e nas pessoas" (p.56).
Dessa forma, Quéré (2005), a partir de Dewey, observa que os acontecimentos fazem emergir "campos problemáticos", que demandam esse trabalho hermenêutico, um "inquérito", que produzirá narrativas e explicações, orientando tanto a ação dos sujeitos quanto sua compreensão de novas ocorrências. Diz Quéré (2005):

\section{Se a maior parte dos acontecimentos se inscreve em campos problemáticos já constituídos, que perduram enquanto os problemas e as respecti- vas causas se mantêm, também novos campos problemáticos se constituem com a emergência de acontecimentos, nomeadamente a partir do trabalho realizado em torno deles. (p.72)}

As mídias, nesse caso, atuam na dupla função de "suporte" da identificação e exploração dos acontecimentos e como agentes no debate acerca dos problemas que estes instauram, oferecendo para isso narrativas, provas de verdade, perspectivas. Ao mesmo tempo, observa Rebelo, as mídias contribuem para a naturalização dos acontecimentos, ou seja, para sua apropriação pelos sujeitos, fabricando adesões e produzindo uma história "fragmentada", "numa continuidade de mutações incessantes" (2005, p.58).

Nessa perspectiva, as notícias podem ser vistas sob um duplo olhar: em relação aos acontecimentos que lhes antecedem, elas, como narrativas, já são resultado de uma ação hermenêutica que os transforma em fato. Imagem do acontecimento, portanto, a notícia põe em circulação leituras, explicações, uma visão peculiar da economia de tensões 
nele presentes. Por outro lado, como aponta Mouillaud, os acontecimentos podem se tornar, "a sombra projetada de um conceito produzido pelo sistema de informação" (2002, p.51). Ao produzir uma notícia, o jornalismo opera uma leitura, um enquadramento do mundo que produz sua visibilidade, ou seja, faz emergir o acontecimento como informação. Essa operação, lembra Mouillaud, constitui uma realidade discursiva, um campo dotado de profundidade, pois encerra em seu interior um referente e um relevo, e um extra-campo, um conjunto de referências que contextualizam e tornam possível a visibilidade almejada.

Nesse processo, é importante ressaltar, a opacidade é elemento fundamental, pois ao mesmo tempo em que as notícias recortam da cena dos acontecimentos uma superfície, elas ocultam aquilo que seu enquadrar não alcança. Mouillaud reconhece que todo o esforço narrativo não é capaz de apreender a totalidade e complexidade do mundo que enquadra. Para ele, o que as notícias fazem é tentar dar conta, linearmente, de toda a dinâmica do acontecimento a partir de seus fragmentos, que são organizados segundo o saber jornalístico. 0 visível seria 0 "fato", aquilo que chega ao leitor, mas diante da impossibilidade de se apreender a totalidade do acontecimento, seus outros fragmentos permaneceriam como uma sombra, seu invisível.

A "produção de visibilidade" apontada por Quéré revela-se propriamente como uma operação de construção, uma vez que a mídia noticiosa precisa de acontecimentos, de gerar notícias no ritmo marcado de sua periodicidade. A operação de enquadramento do mundo, na peculiaridade de suas condições, é um gesto interpretativo a partir do qual acontecimentos emergem. Esse enquadramento se dá em função de expectativas de recepção, ou seja, orienta-se em função de imagens e posturas presumidas do receptor, consumidor final desse produto em oferta. Assim, entende-se que as notícias são acontecimentos para seus receptores, que, por sua vez, desenvolvem diferentes estratégias para interpretá-las, para lidar com suas demandas, numa cadeia incessante em que cada ocorrência pode fazer emergir uma articulação peculiar de tempos e explicações.

Considerando a mediatização da sociedade contemporânea - em que todos os acontecimentos já ocorrem incorporando, em maior ou menor grau, a presença das mídias -, é certo que, como aponta Mouillaud, os agentes sociais já programem os acontecimentos de modo que eles surjam palatáveis às condições do sistema mediático. Isso não é retirar seu caráter polissêmico - ou, nos termos de Quéré, reduzir seu poder hermenêutico. Ao contrário, é adicionar um elemento a mais na trama de tensões e linhas de fuga e força que tecem os nós dos acontecimentos. Dessa forma, mesmo que se constitua como "sombra projetada" de um agir mediático ou mediatizado, 0 acontecimento mantém sua capacidade de ir além da operação 
de enquadramento que 0 gerou. 0 próprio

Mouillaud já havia observado o quanto que 0 enquadramento mediático não se constitui como um contêiner rígido, mas como um gesto de construção que comporta rupturas e resistências.

Assim, mesmo acontecimentos programados, como as manifestações relativas ao Dia Mundial de Combate à Aids, por exemplo, surgem como desafiadores da ação jornalística devido à sua complexidade, por se constituírem, nesse caso específico, numa espécie de nó que envolve a saúde individual e pública, a ciência, a medicina, o Estado, a sociedade civil, os direitos humanos, a política, a moral, a economia e a sexualidade. Ao serem produzidas como notícia, tais manifestações ao mesmo tempo ganham relevo, visibilidade e opacidade ao sabor das tensões do sistema mediático e passam circular como narrativas, como artefato semiótico.

É essa realidade discursiva, fruto de operações lingüísticas, que é ofertada ao receptor e que deseja, para não dizer necessita, de sua adesão para se autenticar como verdadeira. Assim, as notícias devem ser concebidas como espaços de negociação, que envolvem diversos atores sociais e entre eles, de modo privilegiado, está o receptor. Assim, cada mídia, cada programa ou produto, manifesta uma experiência da vida social e a oferta aos seus receptores, numa relação que é menos de manipulação e mais de apropriação mútua. Em outras palavras, como produto de linguagem, 0 acontecimento noticioso exige que 0 seu receptor realize operações que lhe atribuam sentido e 0 (re)insiram no cotidiano. Para tanto, busca antecipar, orientar, conduzir, apropriar-se do gesto de recepção à espera de que o receptor tome a notícia para si, dê-lhe validade, autentique-a.

\section{Estratégias de autenticidade}

No caso específico do Dia Mundial de Luta contra a Aids, em $1^{\circ}$ de dezembro o Jornal Nacional apresentou duas notícias, em seu quarto bloco, que foram antecedidas de chamadas na escalada e no final de cada um dos três primeiros blocos. A primeira (01'47") narra o sucesso da implementação de um teste de sangue que identifica mães soropositivas a tempo de prevenir a contaminação de suas crianças, durante 0 parto ou o pós-parto, pelo vírus HIV. A segunda (01'24") traz um rápido panorama - primeiro nacional, depois mundial - das ações, falas e manifestações ocorridas no dia primeiro de dezembro. A primeira matéria começa com a entrevista de duas jovens, não identificadas (somente suas sombras foram projetadas), que se descobriram soropositivas no início de uma gravidez. Sem explorar 0 drama das mães, as falas foram ordenadas para apresentar a idéia de que a transmissão do vírus pode ser evitada com 0 tratamento adequado. Já segunda matéria começa no Rio de Janeiro, onde um enorme laço vermelho foi estendido sobre 0 Cristo Redentor. A seguir, mostra o Obelisco do Ibirapuera, em São Paulo, e a Casa Branca, em Washington, também decorados com o laço. 
0 panorama segue então para a China, depois para a África do Sul e volta a Nova York, que se revela como o único espaço realmente visitado pelo repórter, e depois segue para lugares não identificados, dos quais foram exibidas imagens de manifestantes, de diversas culturas e religiões que, segundo o discurso na matéria, estariam "unidas" para exigir melhores tratamentos contra um "inimigo comum".

Conforme afirma Antônio Fausto Neto (1999), a inteligibilidade da Aids é, em grande parte, construída pela mídia, que articula saberes e poderes distintos, emitidos por atores sociais que, na concepção do jornalismo, teriam autoridade para falar do tema. Isso faz com que a Aids seja, para o pesquisador, um fenômeno midiático e discursivo, que "resulta de diferentes falas que foram e são produzidas por diferentes instituições..." (1999, p. 20). Considerando a organização que marca eventos como o Dia de Luta, no qual todas as ações são planejadas pensando-se na sua publicização midiática, percebe-se uma ação programada, estratégica, com fins específicos e que resultam de uma leitura sobre aspectos importantes da Aids no mundo contemporâneo. A ação dos manifestantes de colocar laços vermelhos gigantes no Cristo Redentor e na Casa Branca indica claramente a existência de um acontecimento preparado para ser visualizado como notícia. Apesar dessa ação estratégica, esse acontecimento preserva sua polissemia, ou seja, abre-se a uma multiplicidade de sentidos e abordagens. Afinal, como dito anteriormente, o Dia Mundial de Luta contra Aids é um acontecimento que se apresenta como resposta a outro, o da própria síndrome, sendo que ambos trazem a articulação de aspectos e relações bastante diversos na vida social. A Aids pode ser vista assim como um campo problemático peculiarmente desafiador e os acontecimentos dela derivados surgem vinculados a esses desafios.

As notícias exibidas pelo Jornal Nacional são narradas por meio do encadeamento de um fragmento no outro, num modelo linear típico, estruturado com começo, meio e fim. Nota-se também que as narrativas trazem uma espécie de final feliz, um tom otimista quanto ao futuro. Observa-se então, nessas narrativas, um jogo de identidade e identificação. É a partir da identidade do Jornal Nacional, personificada nos âncoras e repórteres, que as demais identidades se constituem. Repetindo-se diaa-dia, notícia a notícia, o Jornal Nacional traz um modo de narrar que sustenta a variação de edições e de personagens e, ao mesmo tempo, facilita a identificação de telespectador. Nesse jogo, uma estratégia freqüente consiste no modo de construção das personagens narrativas. 0 espectador que sempre assiste ao programa já espera, durante a enunciação, que a história de um indivíduo vivenciando a ação narrada seja introduzida. Ou seja, se o pão francês sobe de preço, certamente aparecerá uma dona de casa, que consome o pãozinho todos os dias no café da manhã, reclamando da alta e traçando planos 
para superar o problema. Tratar-se-ia, então, de uma estratégia de singularização, em que o tema geral e as perspectivas que a notícia apresenta aparecem encarnadas em figuras específicas. Pode-se inferir inclusive que essa singularização é utilizada para tornar o relato mais acessível ao espectador, acionando sua identificação com 0 que é narrado.

Contudo, é importante ressaltar que essa "singularização" é, antes de tudo e talvez contraditoriamente, "genérica". Ou seja, as personagens têm pouca força, pois servem à necessidade da narrativa: elas contribuem para confirmar o que o telejornal afirma sobre 0 mundo. A complexidade e a singularidade dos indivíduos são, então, apagadas pelo lugar ou papel social que passam a representar na narrativa. Ainda que a senhora que reclama do aumento do pão tenha nome, sua identidade é de dona de casa, um "tipo" social que 0 telejornal oferece à fácil identificação do telespectador. Nesse modo de construção das personagens, observam-se, então, dois grandes grupos: aqueles que detêm algum poder de fala e aquelas cuja aparição é determinada pela leitura do mundo apresentada na notícia. No primeiro caso, têm-se claramente as autoridades instituídas - chefes de estado, ministros, pessoas que ocupam postos chave nas instituições sociais e que as representam. No segundo caso, tem-se uma galeria de tipos que compõem uma imagem da população brasileira, do "povo".
No dia 31 de março de 2008, por exemplo, das 24 matérias que compunham a edição, 17 eram centradas nesses "tipos" sociais. Uma delas, que tratava das dificuldades de atendimento à população carioca diante do surto de dengue, trazia a epopéia de um pai em busca de socorro para seu filho. Ao acompanhar o périplo desse pai por vários hospitais no Rio, a reportagem denunciava 0 descaso das autoridades com a população e se organizava em torno de tipos fixos: pai, filho, doentes nas filas, atendentes. As falas e as imagens das personagens eram consoantes com seus papéis na narrativa. Em contraponto a elas, por sua vez, 0

Secretário Estadual de Saúde surgia com seu nome em legenda e com uma fala forte, de posicionamento autorizado sobre a situação.

No caso das notícias sobre a Aids, essa estratégia se repete com uma variação significativa. As duas jovens sem rosto da primeira matéria representariam bem as mães soropositivas que, apesar das dificuldades, conseguem prevenir a contaminação dos filhos e "gerar crianças saudáveis". Já os manifestantes brasileiros, norte-americanos, europeus e asiáticos que demandavam mais atenção do Estado para a prevenção e tratamento da Aids não tiveram a mesma sorte. Como nenhuma fala direta deles foi apresentada, a matéria manteve um tom genérico e impessoal e como que se remeteu a um personagem maior, "todos os povos", valorizando um suposto esforço coletivo, do qual 0 receptor é fundamentalmente um espectador. 
Independentemente de como os discursos se configuraram, portanto, fica claro que a fala de todos os entrevistados foi mobilizada de acordo com a intenção da notícia de apresentar a Aids como grave doença social, mas com perspectivas de melhoras.

Se pensarmos como Mouillaud (2002), sobre como o jornal ordena os acontecimentos no espaço e no tempo, chegamos inevitavelmente à noção de mapa, um mapa que seria construído pelo jornalismo de acordo com o modo como ele organiza 0 mundo e 0 apresenta ao espectador. Mouillaud sustenta esta idéia ao comparar a disposição das notícias em um jornal a uma disposição do mundo: "Do leitor, poder-se-ia dizer que ele é "posto no mundo" pelo jornal [...] na medida em que é referido a uma totalidade que o envolve" (p.70). 0 mapa construído pelo Jornal Nacional orienta então os telespectadores sobre 0 que está próximo e 0 que está distante, sobre qual é o seu - do jornal e do telespectador - lugar no mundo. Na notícia sobre as manifestações de luta contra a Aids, 0 Brasil aparece metropolitano, significativamente representado pelo Cristo Redentor e pelo Obelisco do Ibirapuera.

Analisando as matérias sobre a Aids e outras, podemos dizer que as estratégias narrativas são mobilizadas pelo telejornal visando reforçar 0 vínculo que se estabelece entre o programa e 0 telespectador, a partir desta distinta percepção do ver. Para Robert Stam, esses seriam alguns dos recursos que contribuem para a construção de um acontecimento autêntico, por serem "detalhes estratégicos destinados a produzir uma sensação de verossimilhança" (STAM, 1985: 81), que atendem aos "efeitos de realidade" trabalhados pelos telejornais. "0 telejornal harmoniza detalhes autenticadores que criam a ilusão ótica de verdade. A acurácia na representação dos detalhes é, na verdade, menos importante do que o mero fato de que esses detalhes existam" (STAM, 1985, p.81)

\section{Espaços e contatos}

A verossimilhança, marcada nas palavras de Stam pelo detalhe aparentemente insignificante já identificado por Barthes na literatura realista, necessita, na televisão, de outros elementos que assegurem sua eficácia. 0 próprio Stam observa que o telejornal produz - ou deseja produzir - um "nós fictício" que aproxima espectador, apresentadores, repórteres, personagens, fazendo com que uns e outros, unidos por laços de identificação, sejam habitantes de um mundo comum. No território peculiar da realidade televisiva, um dos elementos fundamentais para sua existência e estabilidade é o contato, uma modalidade de interação menos "racional" e mais sensível e afetiva.

Nesse sentido, uma das observações mais instigantes de Eliseo Verón (2001) sobre a tevê diz respeito ao caráter metonímico do contato televisivo, marcado pela organização dos signos audiovisuais em função do corpo do 
telespectador. Segundo ele, a televisão, quando pretende falar do real, alicerça-se sobre 0 contato estabelecido entre os corpos da tela e dos espectadores, de modo a se estabelecer uma relação de contigüidade entre 0 espaço televisual e 0 doméstico. Nessa operação, é significativa a ampliação do espaço televisual, que gradualmente aumenta sua profundidade e, pelo menos de modo aparente, rompe com a bidimensionalidade que 0 caracteriza.

Ao longo de 2007 e 2008, aliás, a tela do Jornal Nacional foi pouco a pouco adquirindo mais amplitude, acentuando seus "níveis internos", seus espaços encaixados que muito se assemelham a uma estrutura em abismo. Essas dimensões superpostas são surpreendentes à primeira vista e se manifestam em diferentes momentos e graças a diversos recursos. Um dos mais conhecidos é certamente o da passagem, em que 0 locutor/apresentador chama um repórter, que surge na tela da tevê, mas fora do estúdio, aparentemente na "cena dos acontecimentos". Na passagem, opera-se um fenômeno curioso, em que o repórter, ao invés de levar a tevê para a rua, traz "o mundo" para dentro da tela, para aquele espaço liminar no qual o locutor e o telespectador já estão. Nessa operação, o espaço externo à tevê é reconfigurado, reorganizado em função das condições tecnológicas e necessidades narrativas do telejornal.

Significativamente, as imagens da rua são construídas como as personagens humanas: respondem a tipos genéricos, sendo freqüentemente pouco singulares. Verifica-se aqui a mesma operação observada antes: as imagens que compõem as passagens ou se remetem a tipos ou a representações autorizadas, já reconhecidas. Assim, por exemplo, ao mostrar a alta dos preços, o telejornal traz imagens de gôndolas, frutas e produtos que produzem na superfície da tela um "supermercado" qualquer, facilmente identificável por qualquer um. No caso de uma das matérias sobre o Dia Mundial de Combate à Aids, a passagem foi feita por uma repórter dentro de um laboratório. 0 telespectador não pode afirmar, por exemplo, se esse laboratório da passagem é o mesmo no qual os testes de HIV são feitos - mas a enunciação parece ser visualmente mais autêntica, de algum modo, quando ocorre dentro destas condições. Quando a narrativa se passa em lugares específicos, como São Paulo ou Brasília, por exemplo, recorre-se, conforme a necessidade narrativa, ou a imagens de avenidas, prédios e favelas que poderiam ser de qualquer grande cidade, ou a prédios ou monumentos que metonimicamente fazem ver na tela 0 "centro de poder" econômico ou político. Numa passagem sobre as notícias do Poder Executivo, assim, é bastante recorrente 0 repórter postar-se frente ao Palácio do Planalto.

Na impossibilidade de trazer todo o mundo para o pequeno espaço da tela, a televisão então, recorta-0 e produz uma realidade televisiva que demanda o reconhecimento fácil do espectador. Este vê emergir no seu espaço doméstico não 
um outro mundo - estranho, diferente - mas 0 "seu lugar", cenas que compõem o mapa mundi em que habita. Para que as operações de reconhecimento e identificação das cenas da passagem sejam eficazes, é fundamental que o espectador esteja habituado com os recortes e condensações freqüentemente usados e repetidos. Nesse sentido, é a formatação do olhar do espectador que está em questão e que faz com que as relações entre campo e extra-campo, entre outras, sejam naturalizadas e pacificadas, de modo que a continuidade desejada se mantenha: que a imagem do Palácio do Planalto ao mesmo traga Brasília e a Presidência da República para a tela da tevê e que continue no cenário azul dos apresentadores e no espaço doméstico dos telespectadores.

Esse cenário azul, aliás, cada vez mais adquire relevo. Sem necessariamente ter que "puxar" imagens do mundo, a tela da tevê se amplia também pela presença cada vez mais constante de imagens digitais, produzidas por computação gráfica. A própria imagem em que os apresentadores surgem se dirigindo ao espectador tem pelo menos quatro níveis: um próximo, em que aparecem seus nomes e os dos repórteres e dos personagens, sempre antecedidos pela logomarca do telejornal; um segundo, que remete à bancada em que estão, um terceiro, em que a logomarca se impõe à vista de todos, às vezes sendo substituídas por grafismos que identificam genericamente 0 assunto tratado; e, por fim, a cozinha do telejornal, em que se vêem mesas, computadores e jornalistas. Nesse mundo em escala, observa-se, por um lado, o quanto que 0 espaço do telejornal se amplia e se naturaliza ao olhar do espectador: as letras voadoras que compõem a logo não causam medo, mas identificação. Por outro lado, a continuidade sugerida entre 0 espaço televisual e 0 doméstico adquire mais densidade, oferecendo mais opções para atrair e localizar o olhar do espectador.

A tela plana da tevê, portanto, fragmenta-se em mais de um espaço, numa operação em que as imagens digitais passaram são fundamentais e cada vez mais freqüentes. Diante dos olhos do espectador e ao lado dos apresentadores, gráficos e tabelas se formam, muitas vezes acompanhados de movimentos de câmera. De certo modo, a tela da tevê se conforma cada vez mais, como já havia antecipado Soulages (2002), de modo semelhante a um portal da web, individualizando o percurso do olhar do telespectador e criando mais possibilidades de contato. A presença maior de imagens digitais acentua ainda mais a natureza distinta, artificial, da realidade televisiva, que, ao absorver modos de enunciação diversos, passa a se remeter a outros sistemas mediáticos e a constituir-se como um mundo próprio. Essa realidade discursiva, cada vez mais fabricada pelos recursos narrativos e tecnológicos e pelas condições mercadológicas, necessita do olhar do telespectador para que se naturalize, para que se integre ao cotidiano sem maiores traumas. 
Observa-se, então, que 0 acontecer da realidade televisiva, seja no âmbito geral do telejornal ou na forma da notícia, é marcado por uma autoreferencialidade peculiar, certamente porosa ao mundo e às suas tensões. Em outras palavras, a auto-referencialidade televisiva não se afirma na simples desconsideração das demais realidades sociais, mas à submissão dessas ao modo de dizer, às necessidades narrativas do telejornal e ao modo cada vez mais intermediático de sua interlocução. A ampliação dos espaços televisuais oferece-se assim não como uma quebra dessa auto-referencialidade, mas, ao contrário, à sua intensificação e à demanda cada vez maior de contato e participação do telespectador, instância final e autenticadora desse mundo.

Se os acontecimentos são necessariamente polissêmicos e reivindicam uma ação hermenêutica, a realidade discursiva performada pelo telejornal ao mesmo tempo oferece-se como resposta, como um locus em que pelo menos parte do problema está, se não resolvido, pelo menos pacificado. Para que isso de fato se dê, convida-se o telespectador que passeie por esse mundo composto por diversos planos convergentes, em que muito acontece, mas que pouco trabalho exige de quem nele habita. 0 perigo, a dor, o desafio estão do lado de lá, em outro lugar, naquele outro mundo, feliz ou infelizmente habitado por telespectadores de carne e osso.

\section{Referências bibliográficas}

ALLEN, Robert C. Reflexões sobre estudos de televisão do meu local de observação. Cadernos de Televisão, Rio de Janeiro, Instituto de Estudos da Televisão, n. 1, p. 8-22, jul. 2007.

BARTHES, Roland. A morte do autor. 0 rumor da língua. Lisboa: Edições 70, 1987, p. 49-53.

CANNITO, Newton. Potenciais da linguagem da

TV digital. Cadernos de Televisão, Rio de Janeiro, Instituto de Estudos da Televisão, n. 1, p.83-92, jul. 2007.

CASSETTI, Federico; ODIN, Roger. De la paléo- à la néo-télévision.Communications. Paris, EHESS, n.51, p. $9-26,1990$.

EC0, Umberto. Viagem na irrealidade cotidiana. Rio de Janeiro: Nova Fronteira, 1984.

\section{FAUSTO NETO, Antônio. Comunicação e mídia} impressa: estudo sobre a AIDS. São Paulo: Hacker, 1999.

IMBERT, G. El zoo visual: de la television espetacular a la televisión especular. Barcelona: Gedisa, 2003.

JOST, François. Seis lições sobre a televisão. Porto Alegre:Sulina, 2004.

LEAL, B.S. Reflexões sobre a imagem: um estudo de caso. E-compós, Brasília, Associação Nacional dos Programas de Pós-Graduação em Comunicação, vol. 5, abr. 2006. Disponível em: < http://www.compos.org.br/ seer/index.php/e-compos/issue/view/5> Acesso em: 28 ago. 2008.

MOUILLAUD, Maurice. 0 jornal, da forma ao sentido. Brasília: Universidade de Brasília, 2002.

QUÉRÉ, Louis. Entre facto e sentido: a dualidade do acontecimento. Trajectos, Lisboa, Instituto Superior das Ciências do Trabalho e da Empresa, n.6, p. 59-76, 2005.

REBEL0, J. Apresentação. Trajectos, Lisboa, Instituto Superior das Ciências do Trabalho e da Empresa, n. 6, p. $55-58,2005$. 
SOULAGES, Jean-Claude. A formatação do olhar.

In: MACHADO, Ida Lúcia; MARI, Hugo; MELLO,

Renato (orgs). Ensaios em análise do discurso. Belo

Horizonte: Núcleo de Análise do Discurso - FALE/

UFMG, 2002, p. 267-281.

STAM, Robert. 0 telejornal e seu espectador. Novos

Estudos, São Paulo, CEBRAP, n. 13, 74-87, out. 1985.

VERÓN, E. El cuerpo de las imágenes. Bogotá: Norma

Editorial, 2001. 
Journalism on tv and the authentication of real: strategies, spaces and events

\section{Abstract}

This article seeks to identify and evaluate some strategies for authentication of the news on television, having in mind particularly the relationship involving the production of journalistic events. The reflections are based on analysis of some news of TV Globo's Jornal Nacional, broadcasted throughout 2007 and 2008.

\section{Keywords}

Television. Journalism. Narrative. Event.

\section{Periodismo em televisión y autenticación de lo real: estrategias, espacios y acontecimientos}

\section{Resumen}

El artículo busca identificar y evaluar algunas estrategias de autenticación de la noticia en el periodismo de televisión, teniendo en cuenta especialmente las relaciones que envuelven la producción del acontecimiento periodístico. Las reflexiones parten de análisis de notas y procedimientos de Jornal Nacional, de TV Globo, durante 2007 y 2008.

\section{Palabras clave}

Televisión. Periodismo. Narrativa. Acontecimiento. 


\section{Expediente}

A revista E-Compós é a publicação científica em formato eletrônico da Associação Nacional dos Programas de Pós-Graduação em Comunicação (Compós). Lançada em 2004, tem como principal finalidade difundir a produção acadêmica de pesquisadores da área de Comunicação, inseridos em instituições do Brasil e do exterior.
E-COMPÓS I www.e-compos.org.br I E-ISSN 1808-2599

Revista da Associação Nacional dos Programas de Pós-Graduação em Comunicação. Brasília, v.11, n.2, maio/ago. 2008.

A identificação das edições, a partir de 2008 passa a ser volume anual com três números.

\section{CONSELHO EDITORIAL}

\section{Afonso Albuquerque}

Universidade Federal Fluminense, Brasil

Alberto Carlos Augusto Klein

Universidade Estadual de Londrina, Brasi

Alex Fernando Teixeira Primo

Universidade Federal do Rio Grande do Sul, Brasi

Alfredo Vizeu

Universidade Federal de Pernambuco, Brasil

Ana Carolina Damboriarena Escosteguy

Pontifícia Universidade Católica do Rio Grande do Sul, Brasil

Ana Silvia Lopes Davi Médola

Universidade Estadual Paulista, Brasil

André Luiz Martins Lemos

Universidade Federal da Bahia, Brasil

Ângela Freire Prysthon

Universidade Federal de Pernambuco, Brasi

Antônio Fausto Neto

Universidade do Vale do Rio dos Sinos, Brasil

Antonio Carlos Hohlfeldt

Pontifícia Universidade Católica do Rio Grande do Sul, Brasil

Arlindo Ribeiro Machado

Universidade de São Paulo, Brasil

César Geraldo Guimarães

Universidade Federal de Minas Gerais, Brasi

Cristiane Freitas Gutfreind

Pontifícia Universidade Católica do Rio Grande do Sul, Brasi

Denilson Lopes

Universidade Federal do Rio de Janeiro, Brasil

Eduardo Peñuela Cañizal

Universidade Paulista, Brasil

Erick Felinto de Oliveira

Universidade do Estado do Rio de Janeiro, Brasil

Francisco Menezes Martins

Universidade Tuiuti do Paraná, Brasil

Gelson Santana

Universidade Anhembi/Morumbi, Brasi

Hector Ospina

Universidad de Manizales, Colômbia

leda Tucherman

Universidade Federal do Rio de Janeiro, Brasil

Itania Maria Mota Gomes

Universidade Federal da Bahia, Brasil

Janice Caiafa

Universidade Federal do Rio de Janeiro, Brasil

Jeder Silveira Janotti Junior

Universidade Federal da Bahia, Brasil
John DH Downing

University of Texas at Austin, Estados Unidos

José Luiz Aidar Prado

Pontifícia Universidade Católica de São Paulo, Brasil

José Luiz Warren Jardim Gomes Braga

Universidade do Vale do Rio dos Sinos, Brasi

Juremir Machado da Silva

Pontifícia Universidade Católica do Rio Grande do Sul, Brasil

Lorraine Leu

University of Bristol, Grã-Bretanha

Luiz Claudio Martino

Universidade de Brasília, Brasil

Maria Immacolata Vassallo de Lopes

Universidade de São Paulo, Brasil

Maria Lucia Santaella

Pontifícia Universidade Católica de São Paulo, Brasil

Mauro Pereira Porto

Tulane University, Estados Unidos

Muniz Sodre de Araujo Cabral

Universidade Federal do Rio de Janeiro, Brasil

Nilda Aparecida Jacks

Universidade Federal do Rio Grande do Sul, Brasil

Paulo Roberto Gibaldi Vaz

Universidade Federal do Rio de Janeiro, Brasil

Renato Cordeiro Gomes

Pontifícia Universidade Católica do Rio de Janeiro, Brasil

Ronaldo George Helal

Universidade do Estado do Rio de Janeiro, Brasil

Rosana de Lima Soares

Universidade de São Paulo, Brasil

Rossana Reguillo

Instituto Tecnológico y de Estudios Superiores do Occidente, México

Rousiley Celi Moreira Maia

Universidade Federal de Minas Gerais, Brasil

Sebastião Carlos de Morais Squirra

Universidade Metodista de São Paulo, Brasil

Simone Maria Andrade Pereira de Sá

Universidade Federal Fluminense, Brasil

Suzete Venturelli

Universidade de Brasília, Brasil

Valério Cruz Brittos

Universidade do Vale do Rio dos Sinos, Brasil

Veneza Mayora Ronsini

Universidade Federal de Santa Maria, Brasil

Vera Regina Veiga França

Universidade Federal de Minas Gerais, Brasil
COMISSÃO EDITORIAL

Ana Gruszynski I Universidade Federal do Rio Grande do Sul, Brasil João Freire Filho I Universidade Federal do Rio de Janeiro, Brasil Rose Melo Rocha I Escola Superior de Propaganda e Marketing, Brasil

\section{CONSULTORES AD HOC}

Aníbal Bragança I Universidade Federal Fluminense, Brasil Gisela Castro I Escola Superior de Propaganda e Marketing, Brasil

Gislene Silva I Universidade Federal de Santa Catarina, Brasil

Maria Helena Weber I Universidade Federal do Rio Grande do Sul, Brasil

Rosana de Lima Soares I Universidade de São Paulo, Brasil

Tania Hoff I Escola Superior de Propaganda e Marketing, Brasil

REVISÃO DE TEXTO E TRADUÇÃo I Everton Cardoso

ASSISTÊNCIA EDITORIAL E EDITORAÇÃO ELETRÔNICA I Raquel Castedo
COMPÓS I www.compos.org.br

Associação Nacional dos Programas de Pós-Graduação em Comunicação

Presidente

Erick Felinto de Oliveira

Universidade do Estado do Rio de Janeiro, Brasil erickfelinto@uol.com.br

Vice-presidente

Ana Silvia Lopes Davi Médola

Universidade Estadual Paulista, Brasil

asilvia@faac.unesp.br

Secretária-Geral

Denize Correa Araújo

Universidade Tuiuti do Paraná, Brasil

denizearaujo@hotmail.com 